\title{
Drawing from Past Experience to Improve the Management of Future Underground Projects (Pre-print of NAT 2004 Paper)
}

\author{
Chris Laughton \\ Fermi National Accelerator Laboratory, Illinois, USA
}

ABSTRACT: The high-energy physics community is currently developing plans to build underground facilities as part of its continuing investigation into the fundamental nature of matter. The tunnels and caverns are being designed to house a new generation of particle accelerators and detectors. For these projects, the cost of constructing the underground facility will constitute a major portion of the total capital cost and project viability can be greatly enhanced by paying careful attention to design and construction practices.

A review of recently completed underground physics facilities and related literature has been undertaken to identify some management principles that have proven successful in underground practice. Projects reviewed were constructed in the United States of America and Europe using both Design-Build and more traditional Engineer-Procure-Construct contract formats. Although the physics projects reviewed tend to place relatively strict tolerances on alignment, stability and dryness, their overall requirements are similar to those of other tunnels and it is hoped that some of the principles promoted in this paper will be of value to the owner of any underground project.

\section{INTRODUCTION}

Over the past twenty years the particle physics community has built a number of underground projects worldwide. Underground sites are preferred for many experiments because the groundmass overlying the facility acts to block the passage of particles and/or radiation that could otherwise have a deleterious impact on the experiments and/or the surrounding environment. Underground acceleratorbased projects constructed in this timeframe include the Super Proton Synchrotron, the Large Electron Positron and the Large Hadron Collider located at the European Particle Physics Laboratory, in Switzerland and France; various projects at the Deutches. Elektronen-Synchrotron in Germany and the Stanford Linear Accelerator-Collider, Superconducting Super Collider Laboratory and Neutrinos at Main Injector (NuMI) projects in the USA. A number of underground detector sites have also been constructed in this same timeframe, notably including excavations made within existing mine boundaries at the Creighton, Homestake, Kamiokande, and Soudan mines or located adjacent to road tunnels within the Frejus, Mont Blanc and Gran Sasso alpine massifs. The combined underground scope of these projects totals close to $100 \mathrm{~km}$ of tunnel, $10 \mathrm{~km}$ of vertical shaft and numerous chambers and caverns up to $25 \mathrm{~m}$ in span. Sadly, the Superconducting Super Collider (SSC) project, the largest such project so far attempted, was terminated before tunnel construction was complete. This project, perhaps above all others referenced, stands as an excellent example of what can be achieved when good contracting practices tailored to underground construction are adopted.

The physics community is now developing a new set of accelerator projects, including the Tera ElectronVolt Superconducting Linear Accelerator, the Next Linear Collider and the Very Large Hadron Collider. The scope of underground construction for these facilities will be larger than any so far undertaken. Rock tunnel housings as currently envisaged will range in length from approximately 50 to $250 \mathrm{~km}$. In addition, a number of new proposals for detectorbased underground experimental programs are being developed, notably relative to the study of beta and neutrino particles, at sites in Brazil, France, Japan, Russia and the USA.

Effective management of underground design and construction is a critical focus of the planning process as these projects move forward. The goals of this planning are to deliver satisfactory facilities quickly at an affordable price ("better, faster, cheaper's).

\section{UNDERGROUND PLANNING}

The main design and construction phases of a rock tunnel project are shown in the flowchart in Figure 
1. The flowchart is based on that proposed by the International Tunnelling Association and discussed by Lowe (1993).

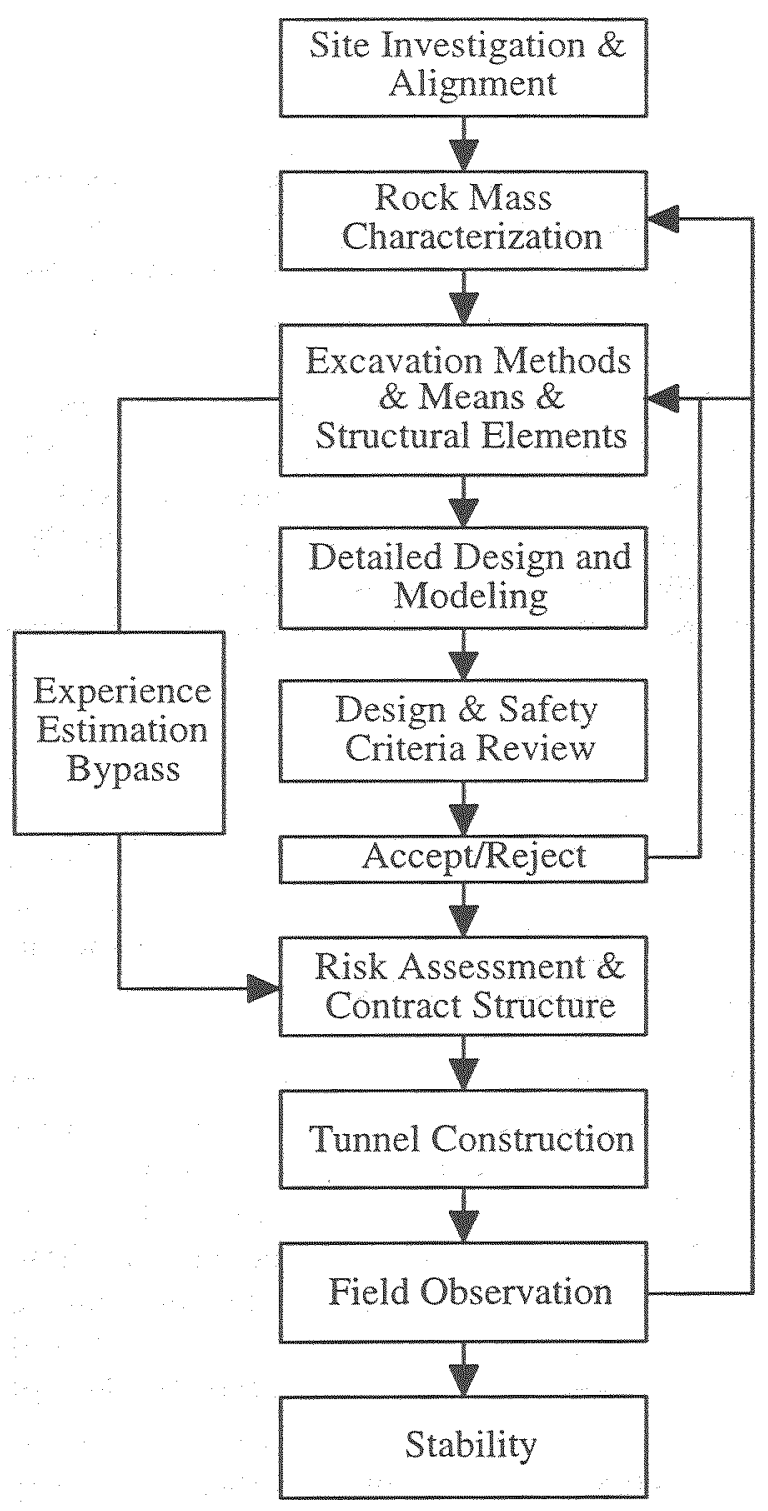

Figure 1: Tunnel Design Process Flowchart

This chart outlines the basic steps in tunnel design and construction from alignment through construction. The flowchart omits reference to some key tasks, notably those associated with estimating and scheduling the work. However, the flowchart does provide a framework for the discussion that follows in which ten general principles are proposed to support an effective tunnel design and construction process.

\section{TUNNELING IS DIFFERENT}

Decisions made at the start of the project will have a great influence on project outcome. As far as a tunnel project is concerned, probably the most critical decisions that need to be addressed at the outset are related to preparing the owner for changes to his normal construction practices. The owner may need some convincing that "normal" business practices may not work so well underground. "Firsttime" tunnel owners, in particular, may see no particular benefit or need to change established ways of doing business and will need convincing that the changes are worth the effort, notably because

- normal design and construction partner(s) may not be able to provide the types and breadth of support necessary for underground construction

- significant resources will need to be expended on site investigation and this work will need to start early

- the bid documents may need to be changed to address the added elements of risk that tunnel construction brings to contracting.

Of course, the underground project may go smoothly or encounter problems irrespective of whether an owner decides to take such precautions. However, such precautions are warranted in order to be responsive to the particular vagaries of the underground project. It will take more effort in the short-term, but will provide for more effective protection of the project over time. If the owner can be convinced of the value of these changes up front, the rest should be easy!

\section{FAMILIARITY WITH LOCAL CONDITIONS}

An early understanding of the host rock mass conditions is a critical element in the design process. To evaluate a site's suitability, regional and locationspecific geologic information will need to be gathered. Information should be collected on rock units, structural folds and faults, groundwater and in situ stress regimes. This geological information will need to be assimilated and interpreted at an early stage in design in order to characterize the rock mass along the alignment(s) and provide input for concept constructability and engineering analyses.

Early acquisition and interpretation of this data is key in support of the design process. This data will help quickly eliminate showstopper situations and avoid much of the "wheel-spinning" (multiple layouts, designs and drafting work) that can occur during design and can consume a sizeable amount of a highly limited resource. 
At the earliest stage of design, shown in Figure 1, adequate site investigation data can generally be drawn from field visits and desk studies. In all but the remotest of areas, published matter can be found to support desk studies (e.g. topographic and geologic, land use mapping and related studies). The design team should also seek to supplement the public domain data sets with specific information on construction projects of a similar nature undertaken in the region. As underlined by Trautman and Kulhawy (1983) such information can most readily be tracked down with the help of a local "geopractitioner" (geologist, engineering geologist, geological engineer). Such individuals will know where the data is and, more importantly, know how to access it. Their familiarity with local formations and involvement on other projects will prove invaluable to the team throughout design and construction. Every design team needs access to such a professional, particularly at the outset of the project when data acquisition and rock mass characterization skills are at a premium.

\section{CONTRACTORS' DESIGN INPUT}

By the time a basic rock characterization has been attained for a site, key underground end-user requirements will also need to have been established. These requirements will typically include a definition of the space and environmental needs of the operating systems as installed. In this regard, the physics end-user is likely to focus on issues such as foundation stability, dryness and alignment given that the success of their operations (accelerator and/or detector) will be highly dependent upon these aspects of the opening's performance. However, before decisions are made and drawings developed defining alignment and cross-sectional requirements, the end user should be made aware that some compromises might be needed if the facility is to be built economically.

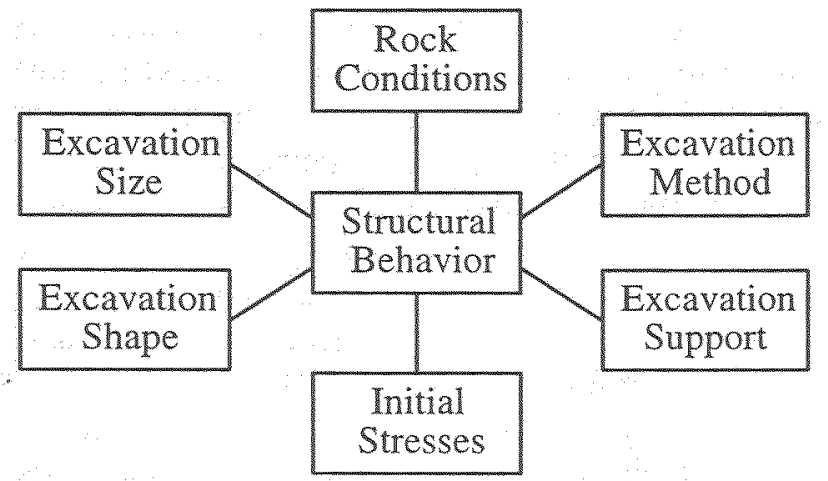

Figure 2: Factors influencing the structural behavior of a tunnel, after Sutcliffe et al. (1990)
Absolutes in precision, stability and watertightness cannot be met easily in a natural, variable rock material and the needs of the experiment will need to be balanced against the practical constraints that the ground mass imposes. To reach the economic compromises discussed above, the requirements setter(s), the designer(s) and builders should ideally have an opportunity to discuss the factors that will impact tunnel behavior, as shown in Figure 2. Ironically, contractors, who undoubtedly have the best appreciation of the constraints of tunnel construction and are the ones who will ultimately price and build the facility, are often completely excluded from all stages of the design process.

A way needs to be found, regardless of the contract format, to solicit the input of the tunnel builder in order to establish an understanding of the process and build-up confidence in the practicality of the design (Atkinson et al. 1997). A tunnel design developed with due regard to the constraints of the construction process results in a more practical design and ultimately provides for a more affordable and lower risk construction product. A more integrated design strategy that involves the contractor can also provide for a more innovative approach to tunneling (Songer and Molenaar, 1996) and help to lower risks associated with unreasonable end-user demands.

\section{CASE HISTORY BENCHMARKNG}

One basic question that needs to be addressed during design is that of precedent. Have similar tunnels been built before? And if they have, what was the outcome? Such questions usually emanate from the owner or their representative who are interested in understanding exactly what kind of situation they have gotten into! These are reasonable questions for which the owner should expect comprehensive answers. Underground projects with similar rock mass and construction methods and means should be researched and made available for the design team to review. Some papers and reports that have compiled tunnel project data bases include the United States National Committee on Tunneling Technology (USNCTT) (1984), Sinha (1986), Parkes (1988), the Association Française des Travaux en Souterrain (AFTES) (1994), and, Nelson et al.(1994). These databases are recommended as a resource for anyone seeking an objective evaluation of case histories, they describe mining performance and problems encountered over the length of the tunnel. In addition to the compiled data base material listed 
above, tunnel construction issues are often reported in a number of industry journals and in conference proceedings such as those of the Australian Tunnelling Conference, International Tunneling Association, North American Tunneling Conference, Rapid Excavation and Tunneling Conference and Tunnelling Symposium.

The owner's confidence in the viability of the "tunnel plan" will be improved if comparable case history data can be compiled and assimilated. The owner will be even more convinced if visits to similar sites can be organized. Examination of case studies also serves as a reality check on plans. A similar case whose outcomes are inconsistent with current projections may raise useful questions or may point to key parameters that differ between the projects.

\section{INTEGRATED ENGINEERING}

In the title of their 1979 paper, Curtis and Rock frame the problem of working on structural linings underground as follows: "Tunnel Linings - Design?" This title is a simple acknowledgement that ground loading on a tunnel lining is difficult to predict even in the most homogeneous of groundmasses. This uncertainty can result in conservatism and/or complexity in design; for example, the use of thick cast-in-place linings to support an otherwise strong rock mass.

The over-design of the final lining is difficult to avoid when loading conditions cannot be predicted with great certainty, Key to minimizing such overdesigns is a consideration of the ground's ability to contribute to the long-term stability of the opening. To this end there is a need to better integrate the geotechnical engineer's knowledge in to the structural engineer's model. Such integration may allow greater opportunity for a discussion of the strengths of the rock mass and ultimately result in the streamlining or even elimination of a "permanent structure."

\section{RISK MANAGEMENT}

Risks associated with underground construction are notoriously difficult to describe and quantify and setting realistic expectations for scope, cost and schedule is always a major challenge. Risks underground are strongly influenced by a number of factors, including the diversity/complexity of the geology, the density of the site investigation coverage, the amount and relevance of compled case history information, the flexibility of the selected mining methods and means and the skill-set of the construction team.

Risk analyses should be performed at critical junctures during design and construction to ensure that risks are properly characterized. Risk analysis should be performed to identify the types of risk to which the project is exposed and provide for an estimate of their frequency of occurrence, and the severity of their impact, ultimately in terms of cost and schedule. Management should use such information to decide upon the type and extent of mitigation required for each type of risk event.

Whatever the level of risk anticipated on the job it is important to find a mechanism that allows this risk to be objectively expressed and communicated to others. To manage such risks effectively the impacts of risk on cost and schedule are perhaps best expressed under a series of "what if" scenarios. These scenarios are needed to complement the deterministic cost and schedule performance reporting systems and will serve to remind management that although underground problems are not shown as activities on the schedule the possibility of encountering them is real!

Even the most thorough site investigation of the most uniform geologic conditions will not be able to completely define the scope of an underground construction contract. Some surprises from the natural material should always be anticipated along the way and an effort should be made to provide management with a clear expression of risk as an integral part of the normal reporting process.

\section{CONTRACTING STRATEGIES}

Nowadays, design and build is commonly held to have distinct advantages over more traditional Engineering-Procurement-Construct contracting, but design and build will not always provide the best solution. Under the right circumstances, a design and build approach may save the owner time and money and offer the individual contractor the best opportunity to integrate the design needs of construction with their preferred methods and means. As Cording (1985) notes, "The separation of design and specifications from the contractor's planning create unnecessary impediments and adds unnecessary costs to the project." However, there are circumstances where the owner may wish to 
maintain greater active control of the underground project through its execution, notably where public interest is high and/or architectural features are an important part of the project. As pointed-out by Boye and Eskensen (2003) the argument for design and build is weakened as public involvement in the permanent works design (geometry, layout; aesthetics) and complexity of the contract interfaces increases. As the needs for prescriptive language in design and construction is reduced, the case becomes stronger for leaving the contractor greater flexibility in his/her choice of methods and means within the framework of the design and build contract option.

\section{ORGANIZING FOR SUCCESS}

All of the issues discussed above, while important, are secondary when compared to the need for assembling and maintaining a good project team to manage the work. Care should be exercised in the selection of all team members whether searched and selected from in-house staff or out-sourced. At a minimum, candidate members should be expected to demonstrate a requisite level of individual and corporate competence, and work products should be provided that exemplify the candidate's ability to fulfill project-specific roles. Focus should be placed on judging the relevance of past experience (similar requirements, geology, methods and means, etc.).

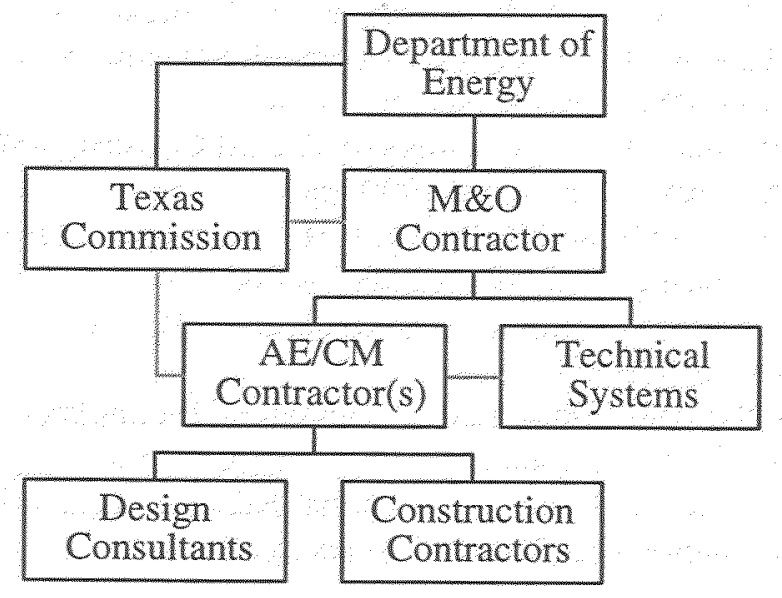

Figure 3: Management Organization for the SSCL, after USNCTT (1989)

When there is inadequate expertise within the owner's existing organization, responsibility for the management of the design and/or construction may be delegated, as shown in Figure 3. Here the SSCL Architect/Engineer and Construction Manager $(\mathrm{AE} / \mathrm{CM})$ team was carefully selected following guidelines setout by the US National Committee on Tunneling Technology, Geotechnical Board
(USNCTT 1989). The selected AE/CM (Parsons Brinckerhoff and Morrison Knudsen) provided a dedicated team of experienced professionals to the SSCL project. The project was managed to cost and schedule up until its termination in the early 1990 's.

\section{THE VALUE OF REVIEWS}

Technical reviews are a common part of most large tunnel projects. They can be regarded as a distraction from the core project objectives, but if properly run they can provide valuable opportunities for improved communication and learning between project members and ultimately result in a better project. Reviews are most likely to be effective if the agenda is established ahead of time and if participants are invited based on their ability to address agenda items. In some instances, an individual may be nominated to play the role of "devils advocate" to encourage and broaden the framework of discussion. Issues should be framed in such a way that participants are not asked to answer leading questions and attention should be paid to ensure that individuals are not placed in positions where conflicts of interest might arise.

The review process should encourage frank and open discussion between participants aimed at comprehensively addressing agenda topics and answering specific questions. Review outcomes should include a single attendee-reviewed document that faithfully records the topics discussed, findings and recommendations... Any review recommendations that require follow-up should be addressed and appropriate actions taken.

\section{LESSONS LEARNED}

Many of the decisions made during the course of a tunnel project are experience-driven. Despite improvements in rock mass modeling and the prediction of mining performance the industry is likely to remain heavily dependent on this "experience factor" for the foresceable future. Within the industry there is an on-going need to share and learn from our collective experiences, both good and bad. The industry, cannot afford to let every owner learn from his/her own mistakes. If past successes and failures go unreported opportunities for improved practices will be lost and the same common errors will continue to be repeated.

A more concerted effort is needed to methodically analyze and openly discuss the underlying reasons for success and failure of tunnel jobs. Sharing these 
experiences would allow the tunneling protagonists the opportunity to get smarter more quickly and allow potential owners better insight in to the workings of the underground construction industry.

\section{CONCLUSIONS}

Digging a hole underground is not as simple as it sounds. Cost and risk are potentially much higher than they are for equivalent surface-based or cut and cover structures. Tunneling really does present the owner with a different set of construction challenges than he/she may be accustomed to dealing with.

At the outset of the tunnel project, focus should be placed on educating the owner to the particular vagaries of the underground contract. As work commences attention should be paid to developing an early appreciation of the site in general and the rock mass in particular. During the design, focus should be placed on properly integrating the enduser and engineering needs of the facility with the construction preferences of the contractor.

For tunneling particular attention should be placed on establishing and updating expectations for costs and schedule performance. Regardless of the contracting strategies and the instruments chosen to mitigate and/or allocate risks, the owner will need to be regularly briefed on issues of project risk as tunnel projects are vulnerable to critical path delays. Reviews can be valuable tools for providing fresh technical and contractual insights to the management team.

During construction, the contract will require active management in order to ensure that contract provisions are met and, that ground conditions are evaluated and timely decisions made as necessary.

At the end of each tunnel job the process and outcome should be objectively reported so that any lessons learned can serve as a reference and guide for other owners and industry professionals alike.

\section{REFERENCES}

AFTES, Working Group No. 4 on Mechanization of the Excavation Process (1994), "Fiche Signalétiques de Chantiers Mécanisếs, Recueil 94"

Atkinson, A., Cavilla J., Wells, J. "Securing the

Contractor's Contribution to Buildability in Design".

Project Report 27, CIRIA. London 1997.

Boye, C. and Eskesen, S.D. (2003) "Specifying

underground Works - the Challenge of Developing the Optimal Requirements." Proceedings

Underground Construction Conference, London

September, 2003 pp.509-520.

Cording, E.J. (1985), "Constraints on Tunneling

Technology," Proceedings of the Conference on

Tunnelling and Underground Transport, Future

Developments in Technology, Economics, and

Policy, Boston, MA, US., April, pp, 121-141.

Lowe, P.T. (1993), "The Planning and Design of the

Prospect to Pipehead Tunnel." Proceedings, 8th

Australian Tunnelling Conference, Sydney,

Australia, 24-26 August, pp. 21-27

National Research Council (1989): "Contracting

Practices for the Underground Construction of the

Superconducting Super Collider", Washington D.C., pages 99.

Nelson, P.P., Y.A. Al-Jalil and C. Laughton (1994),

"Tunnel Boring Machine Project Data Bases and

Construction Simulation," Geotechnical Engineering

Center Report GR. 94-4 to the National Science

Foundation, December.

Parkes, D. B. (1988), "The Performance of Tunnel-

Boring Machines in Rock," Construction Industry

Research and Information Association, Special

Publication No. 62, pages 56.

Songer, A.D., and K.R. Molenaar (1996), "Selecting

Design-Build: Public and Private Sector Owner

Attitudes." Journal of Management in Engineering,

November-December, pp. 47-53.

Sutcliffe, M. L.; S. F. Rogers, R. N. Whittaker and

B. H. Roberts. "Integrated Approach to Geotechnical

Assessment of Rock Tunnel Stability and

Performance." Proceedings of Tunnel Construction '90, London, UK, April 1990, pp. 145-153.

Trautman $\mathrm{CH}$ and Kulhawy, F.H. "Data sources for Engineering Geologic Studies." Bulletin of Association of Engineering Geologists, Vol. XX, No.4, pp 439-454.

US National Committee on Tunneling Technology (1984), "Geotechnical Site Investigations for Underground Projects." National Research Council, Washington DC, National Academic Press. 